\title{
COMPARATIVE ANALYSIS OF SENTIMENT ANALYSIS ON SOCIAL MEDIA
}

\author{
${ }^{1}$ B Ramakantha Reddy \\ Research Scholar \\ Department of SCOPE \\ VIT University, Vellore, India \\ ramakanthareddy.b2016@vitstudent.ac.in
}

\author{
${ }^{2}$ Dr. R Lokesh Kumar \\ Associate Professor \\ Department of SCOPE \\ VIT University, Vellore, India \\ lokeshkumar.r@vit.ac.in
}

\begin{abstract}
For past few years, the World Wide Web has turned into an immense wellspring of client produced content and opinionative information. Utilizing web-based life, for example, Instagram, Facebook, twitter, etc., users share their views and feelings in an advantageous manner. Web-based social networking, for example, Instagram, Facebook, twitter, etc., where a huge number of individuals prompt their individual perspectives in their everyday communication, which may be their assumptions \& sentiments about specific thing. These consistently developing emotional information are, without a doubt, an incredibly rich wellspring of data for any sort of basic leadership method. To computerize examination of such information, region of Sentiment Analysis has been developed. It goes for recognizing opinionative information in the Web \& characterizing it as indicated by their polarities., regardless of whether they convey a positive/negative implication. Assessment Study is an issue of content-based examination, yet there are a few difficulties that make it troublesome when contrasted with conventional content-based investigation This unmistakably expresses there is need of an endeavor to move in the direction of these issues and it has opened up a few open doors for future research for taking care of refutations, concealed assumptions ID, slangs, polysemy. Be that as it may, the developing size of information requests programmed information examination strategies. In this paper, a literature review on various strategies utilized in the Sentiment Analysis is done to comprehend dimension of the work.
\end{abstract}

Keywords - opinion analysis, social media, sentiment analysis.

\section{OVERVIEW}

Sentiment analysis is called as opinion analysis mining in general way, which is a technique to be programmed for discovery of the conclusions embodied in the content, especially in the information digging pitch for the online networking with various applications, including item evaluations and input investigation and client basic leadership and so forth [9]. Presently online life has turned into a noteworthy general sentiment discoverer and dispersal stage. With the quick advancement of Web 2.0, an ever-increasing number of individuals like to prompt their contemplations, perspectives \& method over Internet, which increment the tremendous wellspring of the client created content $\&$ opinionative information.

Influence of this review is valuable for some reasons. In the first phase, the study gives inventorying of a substantial number of late articles as indicated by the methods utilized. This methodology could assist the specialists who need to utilize certain systems in the Sentiment Analysis domain \& select the fitting strategy for an specific application. At long last, the review gives some attention on a certain move associated fields to conclusion examination. This review study is ordered as follows: Section-2 handles various methods of opinion mining \& its associated works.

Some of the issues which are correlated with sentiment analysis areas will be explained in the Section-3. we will finally conclude the review study in the Section-4.

\section{METHODLOGIES OF SENTIMENT ANALYSIS}

Researchers of the paper [1] properly expressed their undertaking, \& translated how to scientifically join social setting and topical setting into the essential forecast show. They explored the opinion-based relationships between the subjects, \& determined to gauge it. The suspicions around societal setting \& contemporary setting are together verified by the theory test on the Twitter informational index they made. At long last, they directed investigations to assess anticipated ScTMF system, \& the trial outcomes showed that both societal setting \& contemporary setting will progress the execution for client subject sentiment forecast.

As indicated by [2] in supposition examination, the execution of Bag of words here and there stays constrained because of some crucial lacks in taking care of the extremity move problematic. They planned a prototype termed double assumption investigation. They previously projected a novel information extension method by making a feeling turned around survey for each preparation and test audit. On this premise, they proposed a double preparing calculation to utilize unique and switched preparing surveys in sets for assessing a classifier, \& a double forecast calculation to order test audits by thinking about opposite directions of the audit. They likewise expanded the DSA system from extremity (positive-negative) grouping to 3-class (positive - negative-unbiased) arrangement, by thinking about the nonpartisan emotions. At long last, they built up a corpus-technique to build a pseudo-antonym lexicon.

Researchers of the paper [3] focused on designing understudies' Twitter presents on get issues and glitches in their instructive encounters. They previously directed a subjective investigation on tests engaged from around $25 \mathrm{~K}$ tweets associated to designing understudies' school life. They discovered building understudies experience issues, for example, lack of social commitment, overwhelming examination burden, and rest insufficiency. In view of these outcomes, we actualized a multi-name characterization calculation to sort tweets mirroring understudies' issues. They at that point utilized the calculation to prepare an identifier of understudy issues from around $35 \mathrm{~K}$ tweets allotted at the place of Purdue University, USA. These works, introduces a methodology 
outcomes which will represent how the normal social media information will offer perceptions into different practices.

Aimed at the gathering of the idea applying the opinion classifier arranged consequences in the low execution. To overcome the component, dumbfound issue in cross-space thought portrayal [4] planned a cross-space supposition classifier using a normally removed thought unstable glossary. They has been done the examinations counter to the SentiWordNet, a lexical source for the words limit. It will shows the made estimation fragile glossary absolutely gets words which prompt same type of presumptions [4].

Scientists saw the past explorations prevalently based on showing and following open evaluation along these lines, they moved well beyond to decipher idea assortments. They wore down twitter dataset. They saw that rising focuses (named frontal territory subjects) inside the supposition assortment periods are exceptionally related to the authentic purposes for the assortments. These closer view subjects can unravel the presumption assortments. In light of this discernment, L-D-A based model, Foreground \& Background L-D-A (F-B-L-D-A), to reveal front line calls attention to channel out establishment subjects. To furthermore progress the comprehensibility of excavated reasons, they situated them concerning "reputation" inside assortment time phase using L-D-A (R-C-B-L-D-A) methodology [5,6].

Researchers exhibited a dual conclusion theme show \& a reparametrized form of the J-S-T called Inverse-J-S-T when a large portion of current ways to deal with estimation order support managed learning. Not at all like directed ways to deal with feeling grouping which regularly neglect to create adequate execution when moving to new spaces, the feebly administered condition of JST makes it exceptionally helpful to different areas [6].

Examination of [7] speaks to that three sorts of information is profitable to thus create the general inclination limit for an hash-tag in reasonable timespan, it especially moves from standard phrase level \& report level thought examination, as well as feeling furthest point of tweets comprising of hash tags, hash names co-occasion association convey \& demanding significance of the hash names to meld underlying 2 sorts of info into a request context, in which all the hashtags will be orchestrated all things considered, they suggest innovative outline show \& inspect 3 construed total gathering estimations for acceptance. Continuing, they exhibit the execution can be incredibly enhanced by means of a redesigned enhancing portrayal in which we use the exacting significance of hash tags as semi-directed data. They managed an authentic educational accumulation involving $29 \mathrm{~K}$ tweets and $2 \mathrm{~K}$ hash labels to demonstrate the viability.

Researchers of [8] have demonstrated that the assumption investigation results delivered by their crossover methods are great contrasted with the dictionary just \& adapting just baselines. For both assessment extremity arrangement \& opinion quality discovery, their pSenti framework, accomplishes high exactness that is extremely near the unadulterated learningbased framework, and a lot higher than the unadulterated vocabulary-based framework. This methodology can join the best of two universes | the solidness just as meaningfulness from a painstakingly structured dictionary, and the high precision from a ground-breaking regulated learning calculation.
Scientists have researched the insightful force of reviews using the film territory as a relevant investigation, and concentrated the issue of envisioning bargains execution using end info excavated from reviews [9]. They recommend Sentiment P-L-S-A (S-P-L-S-A), in which an overview is mentioned as a report made by different covered assessment factors, in order to get the confounding thought of inclinations. They propose a A-R-S-A, an Autoregressive Sentiment Aware model for the arrangements desire. They check for additional development in the precision of gauge by contemplating the eminence aspect, with a consideration on envisioning the idea of an overview without customer gave markers, \& current A-RS-Q-A, an Autoregressive Sentiment and Quality Aware model, to practice evaluations and eminence for forecasting thing bargains execution.

It is serviceable at stock expense of specific associations to be foreseen with typical precision as high as $76 \%$. They anticipated a strategy to burrow Twitter information for responses to the request alike if the expense of a decision of the 30 associations recorded in the NASDAQ \& New York Stock Exchange can truly be foreseen by given $15 \mathrm{M}$ accounts of Twitter posts [10]. We consume sketched out the outline in the Table-I for the diverse kind of work finished in the Sentiment Analysis field. $\mathrm{R}^{*}$ is the reference number.

\section{CHALLENGES AND ISSUES}

\section{A. Incremental Method}

Examination of ongoing information isn't one-time task. At whatever point information is added we have to do examination then for what reason ought not we utilize the past investigation result. Steady methodology enables a current outcome to be refreshed utilizing just new individual information occurrences, without having to re-model previous cases. This might be valuable in the circumstances where the whole data isn't accessible when the information varies after some period.

\section{B. $\quad$ Parallel Processing of Huge Data}

In the event that we partition the calculation into undertakings or procedures that can be executed all the while, at that point there will be an enhancement. in the speed using parallel processing, it is important to accomplish this in assessment examination of huge information of internet-based life, where monstrous texts are distributed each day with the goal that we can use the general processing power. 
TABLE-I: METHODOLOGIES OF SENTIMENT ANALYSIS

\begin{tabular}{|c|c|c|c|c|c|c|}
\hline $\begin{array}{l}\text { Ref } \\
\text { S.No }\end{array}$ & Method & Tools/Approaches & Experimental analysis & $\begin{array}{l}\text { Machine } \\
\text { Learning/ } \\
\text { Lex } \\
\text { analysis } \\
\text { Based(M } \\
\text { L/Lex) }\end{array}$ & $\begin{array}{c}\text { Scope of } \\
\text { Data/Information }\end{array}$ & Data Resource \\
\hline 1 & $\begin{array}{l}\text { Users } \\
\text { keyword } \\
\text { opinion } \\
\text { analysis }\end{array}$ & $\begin{array}{l}\text { Social framework } \\
\text { Topical framework unified } \\
\text { Matrix Factorization }\end{array}$ & $\begin{array}{l}\text { For predicting } \\
\text { unidentified users } \\
\text { subject opinions. }\end{array}$ & LEX & Facebook & $\begin{array}{l}\text { Social Media } \\
\text { Posts }\end{array}$ \\
\hline 2 & $\begin{array}{l}\text { Polarity } \\
\text { change in } \\
\text { sentiment } \\
\text { organization }\end{array}$ & $\begin{array}{l}\text { Dual-sentiment } \\
\text { analysis }\end{array}$ & $\begin{array}{l}\text { Polarity classification } \\
\text { Approach }\end{array}$ & LEX & $\begin{array}{l}\text { Multiple } \\
\text { domain } \\
\text { sentiment } \\
\text { one English } \\
\text { dataset. } \\
2 \text { Chinese } \\
\text { dataset }\end{array}$ & $\begin{array}{l}\text { Amazon } \\
\text { (AWS) }\end{array}$ \\
\hline 3 & $\begin{array}{l}\text { Qualitative } \\
\text { analysis of } \\
\text { huge-scale data } \\
\text { mining } \\
\text { methods }\end{array}$ & $\begin{array}{l}\text { Naïve-Bayes } \\
\text { classification method }\end{array}$ & $\begin{array}{l}\text { It will represent how } \\
\text { the casual social } \\
\text { media information } \\
\text { will give insights. }\end{array}$ & ML & Twitter & Tweets \\
\hline 4 & $\begin{array}{l}\text { Cross domain } \\
\text { sentiment } \\
\text { classification } \\
\text { analysis }\end{array}$ & Quantity based & $\begin{array}{l}\text { To look at the upside of } \\
\text { utilizing an opinion touchy } \\
\text { vocabulary for cross space } \\
\text { conclusion order technique }\end{array}$ & LEX & $\begin{array}{l}\text { Product } \\
\text { ratings }\end{array}$ & $\begin{array}{l}\text { Amazon, } \\
\text { alibaba }\end{array}$ \\
\hline 5 & $\begin{array}{l}\text { To } \\
\text { understand } \\
\text { sentiment } \\
\text { discrepanci } \\
\text { es }\end{array}$ & $\begin{array}{l}\text { L-D-A model, Foreground \& } \\
\text { Background F-B-L-D-A. }\end{array}$ & $\begin{array}{l}\text { To find the different } \\
\text { probable explanations of } \\
\text { public sentiment } \\
\text { Differences. }\end{array}$ & ML & Twitter & Tweets \\
\hline 6 & $\begin{array}{l}\text { Sentiment and } \\
\text { domain } \\
\text { discovery }\end{array}$ & $\begin{array}{l}\text { Inadequately J-S-T } \\
\text { model based on L-D-A }\end{array}$ & $\begin{array}{l}\text { To distinguish notion and } \\
\text { subject all the while from } \\
\text { content }\end{array}$ & ML & $\begin{array}{l}\text { Product ratings, } \\
\text { Cinema } \\
\text { reviews }\end{array}$ & $\begin{array}{l}\text { Amazon, } \\
\text { IMDB library }\end{array}$ \\
\hline 7 & $\begin{array}{l}\text { Hashtag level } \\
\text { sentiment } \\
\text { analysis }\end{array}$ & Support Vector Machine & $\begin{array}{l}\text { To deliver the general idea } \\
\text { furthest point for certain } \\
\text { hashtags in a particular time } \\
\text { phase, which especially } \\
\text { differentiates from standard } \\
\text { sentence-level \& file level } \\
\text { thought examination. }\end{array}$ & ML & $\begin{array}{l}\text { Self-annotation } \\
\text { method to tag } \\
\text { dataset. }\end{array}$ & Tweets \\
\hline 8 & $\begin{array}{l}\text { Sentiment } \\
\text { polarization } \\
\text { classification } \\
\& \text { sentiment } \\
\text { strength } \\
\text { exposure }\end{array}$ & $\begin{array}{l}\text { Hybrid method (lex } \\
\text { based and Machine } \\
\text { learning) }\end{array}$ & $\begin{array}{l}\text { To categorize polarity } \\
\text { and distinguish } \\
\text { sentiment analysis }\end{array}$ & $\begin{array}{l}\text { ML \& } \\
\text { LEX }\end{array}$ & $\begin{array}{l}\text { Software } \\
\text { ratings and } \\
\text { cinema } \\
\text { reviews }\end{array}$ & $\begin{array}{l}\text { CNET, Netflix, } \\
\text { amazon prime, } \\
\text { IMDB }\end{array}$ \\
\hline 9 & Sales prediction & $\begin{array}{l}\text { S-P-L-S-A, A-R-S-Q-A, an } \\
\text { Autoregressive } \\
\text { Sentiment \& Quality Aware } \\
\text { model }\end{array}$ & $\begin{array}{l}\text { To Forecast } \\
\text { Sales Performance }\end{array}$ & ML & Cinema reviews & IMDB \\
\hline 10 & $\begin{array}{l}\text { Forecasting } \\
\text { Stock Price } \\
\text { Movements }\end{array}$ & $\begin{array}{l}\text { NLP } \\
\text { Methods }\end{array}$ & $\begin{array}{l}\text { They anticipated a } \\
\text { strategy to burrow } \\
\text { Twitter information for } \\
\text { responses to the request } \\
\text { alike if the expense of a } \\
\text { decision of the } 30 \\
\text { associations recorded in } \\
\text { the NASDAQ \& New } \\
\text { York Stock Exchange } \\
\text { can truly be foreseen by } \\
\text { given } 15 \mathrm{M} \text { accounts of } \\
\text { Twitter posts }\end{array}$ & ML & Twitter & Tweets \\
\hline
\end{tabular}




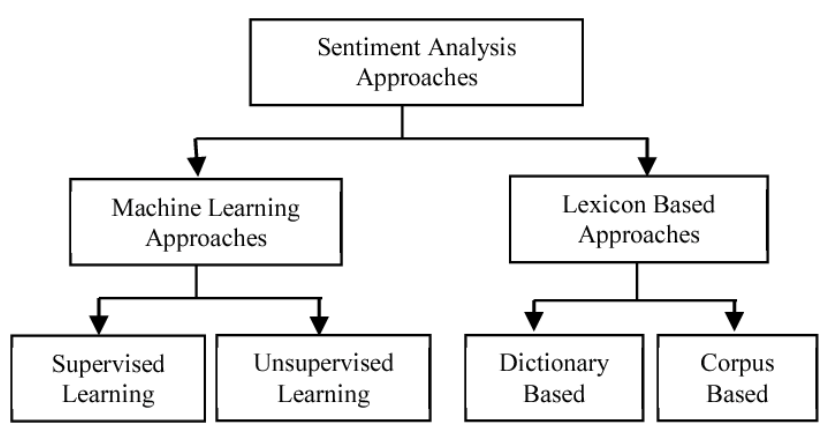

Fig.1. Sentiment Analysis Methods

\section{Reliability/Performance/Homophily}

Practices in web-based social networking are just seen by the follows they leave in web-based life. We seldom watch the driving elements that reason these practices; nor would we be able to talk with people in regards to their practices. Regardless of whether a conduct is investigated via web-based networking media \& related examples are gathered, it's hard to check the legitimacy of these personal conduct standards. Assessment turns out to be significantly all the more trying for enterprises in which critical choices are to be mentioned dependent on objective facts of individual conduct [12].

\section{Acerbity}

Mockery will be used to hurt/disturb or will be used for amusing effect. It suggests incorrect positives for e.g. "Families really light up nuclear family - never turn lights off". Distinguishing joke from verbalizations \& discovery the precise setting correlated ideas is a troublesome duty. It is an entertaining or amusing comment that is apparently lauding someone or something anyway is genuinely inciting or unkind [13].

\section{E. Grammatically Inappropriate Words}

Numerous methodologies that investigate estimations yet barely any work achieved on syntactic blunders. The aftereffects of assumption examination will be upgraded if these kinds of blunders can be planned to address words [14].

F. Examine Author Dissection

Feeling on the way to an objective might be indicated by numerous individuals who can be termed as survey creators. Contingent upon the remarking style of these creators, they ought to be sorted so validity assessment will be simple. In basic leadership this validity assessment is useful [15].

\section{G. Enhancement of prevailing Lex or Updating/Degrading Lex}

Various person's remarks, the performance of estimation analyzer depends upon the precision of the word reference. Modifying of current lexicons is essential to suit new words and wreck the words which are no increasingly for better outcomes. Lexicon extension utilizing proportionate words has a hindrance of the wording losing it fundamental significance after a few emphases [16].

\section{$H$. Managing Noise \& Vitality}

Web based life information are tremendous, uproarious, unstructured, \& dynamic in nature, \& consequently innovative difficulties emerge, presents delegate inquire about issues of mining online life. Distinguishing and evacuation of uproarious information is a difficult errand.

\section{CONCLUSION}

Masses of clients share their emotions via web-based networking media, making it an important stage for following and investigating open conclusion. Web based life is one of the greatest stages where huge texts are distributed each day which makes it a perfect hotspot for catching the assessments towards different inquisitive themes, for example, items, products or superstars, and so on. The primary aim of review study is to give a review of most current apprises in the sentiment analysis examination in social media and grouping strategies and it incorporates the concise talk on the difficulties of assessment investigation for which the work should be finished. We additionally discovered that the majority of the works done depend on AI technique instead of the dictionary-based strategy.

\section{REFERENCES}

[1] Fuji Ren,Ye Wu," Predicting User-Topic Opinions in Twitter with Social and Topical Context", IEEE Trans. on affective computing, vol. 4, no. 4, October-December 2016.

[2] Rui Xia, Feng Xu, Chengqing Zong, Qianmu Li, Yong Qi, and Tao Li,'Dual Sentiment Analysis:Considering Two Sides of One Review", IEEE Trans.on Knowledge and Data Engineering, 2018

[3] Xin Chen,Mihaela Vorvoreanu, and Krishna Madhavan," Mining Social Media Data for Understanding Students' Learning Experiences" IEEE trans. on learning technologies, vol. 7, no. 3, JulySeptember 2015.

[4] Danushka Bollegala, David Weir, and John Carroll," Cross-Domain Sentiment Classification Using a Sentiment Sensitive Thesaurus", IEEE trans. on knowledge and data engineering, vol. 25, no. 8, August 2017.

[5] Shulong Tan, Yang Li, Huan Sun, Ziyu Guan, Xifeng Yan, Jiajun Bu, ,Chun Chen, and Xiaofei He," Interpreting the Public Sentiment Variations on Twitter", IEEE trans. on knowledge and data engineering, vol. 26, no. 5, May 2018.

[6] Chenghua Lin, Yulan He, Richard Everson, Member, IEEE, and Stefan Ru"ger," Weakly Supervised Joint Sentiment-Topic Detection from Text", IEEE trans. on knowledge and data engineering, vol. 24, no. 6 , June 2017.

[7] Xiaolong Wang, Furu Wei, Xiaohua Liu, Ming Zhou, Ming Zhang,' Topic Sentiment Analysis in Twitter: A Graph-based Hashtag Sentiment Classification Approach", ACM, CIKM'11, October 24-28, 2016, Glasgow, Scotland, UK, 2016.

[8] Andrius Mudinas, Dell Zhang, Mark Levene," Combining Lexicon and Learning based Approaches for Concept-Level Sentiment Analysis", WISDOM' 12, August 12, 2016, Beijing, China Copyright 2016,ACM.

[9] Xiaohui Yu,Yang Liu, Jimmy Xiangji Huang, and Aijun An,", Mining Online Reviews for Predicting Sales Performance: A Case Study in the Movie Domain", IEEE Trans.On knowledge and data engineering, vol. 24, no. 4, April 2018.

[10] LI Bing, Keith C.C. Chan, Carol OU," Public Sentiment Analysis in Twitter Data for Prediction of A Company's Stock Price Movements", 2017 IEEE, 11th International Conference on e-Business Engineering.

[11] K. J. Devi, G. B. Moulika, K. Sravanthi and K. M. Kumar, "Prediction of medicines using LVQ methodology," 2017 International Conference on Energy, Communication, Data Analytics and Soft Computing (ICECDS), Chennai, 2017, pp. 388-391.

[12] K. M. Kumar, H. Kandala and N. S. Reddy, "Synthesizing and Imitating Handwriting Using Deep Recurrent Neural Networks and Mixture Density Networks," 2018 9th International Conference on 
Computing, Communication and Networking Technologies (ICCCNT), Bangalore, 2018, pp. 1-6.

[13] B. R. Reddy, Y. Vijay Kumar and M. Prabhakar, "Clustering large amounts of healthcare datasets using fuzzy c-means algorithm," 2019 5th International Conference on Advanced Computing \& Communication Systems (ICACCS), Coimbatore, India, 2019, pp. 93-97, doi: 10.1109/ICACCS.2019.8728503.

[14] G. Meena, D. Sharma and M. Mahrishi, "Traffic Prediction for Intelligent Transportation System using Machine Learning," 2020 3rd International Conference on Emerging Technologies in Computer Engineering: Machine Learning and Internet of Things (ICETCE), Jaipur, India, 2020, pp. 145-148, doi: 10.1109/ICETCE48199.2020.9091758.

[15] T. Karatekin et al., "Interpretable Machine Learning in Healthcare through Generalized Additive Model with Pairwise Interactions (GA2M): Predicting Severe Retinopathy of Prematurity," 2019 International Conference on Deep Learning and Machine Learning in Emerging Applications (Deep-ML), Istanbul, Turkey, 2019, pp. 6166, doi: 10.1109/Deep-ML.2019.00020.

[16] B. Ay, G. Aydın, Z. Koyun and M. Demir, "A Visual Similarity Recommendation System using Generative Adversarial Networks," 2019 International Conference on Deep Learning and Machine Learning in Emerging Applications (Deep-ML), Istanbul, Turkey, 2019, pp. 44-48, doi: 10.1109/Deep-ML.2019.00017. 